\title{
Risk Factors for Medical and Surgical Complications after 1-2-Level Anterior Cervical Discectomy and Fusion Procedures
}

\author{
ANKUR S. NARAIN, BA, FADY Y. HIJJI, MD, BRITTANY E. HAWS, BS, BENJAMIN KHECHEN, BA, \\ KRISHNA T. KUDARAVALLI, BS, KELLY H. YOM, BA, KERN SINGH, MD \\ Department of Orthopaedic Surgery, Rush University Medical Center, Chicago, Illinois
}

\begin{abstract}
Background: Postoperative complications after anterior cervical discectomy and fusion (ACDF) have a significant impact on clinical outcomes and health care resource use. Identifying predictive factors for complications after ACDF may allow for the modification of care protocols to mitigate complication risk. The purpose of this study is to determine risk factors for the incidence of medical and surgical complications up to 2 years postoperatively after ACDF procedures.

Methods: A prospectively maintained surgical registry of patients who underwent primary, 1-2-level ACDF was retrospectively reviewed. The incidence of medical and surgical complications up to 2 years postoperatively was determined. Patients were classified according to demographic, comorbidity, and procedural characteristics. Bivariate Poisson regression with robust error variance was used to determine if an association existed between the incidence of medical or surgical complications and patient characteristics. A final multivariate model including all patient and procedural characteristics as controls was created using backwards, stepwise regression until only those variables with $P$ $<.05$ remained.

Results: A total of 310 patients were included. Upon bivariate analysis, age $>50$ years was identified as a risk factor for medical complications after ACDF procedures. Additionally, bivariate analysis identified ageless Charlson comorbidity index $\geq 2$, operative duration $>60$ minutes, and 2-level procedures as risk factors for surgical complications after ACDF. Upon multivariate analysis, age $>50$ years was identified as an independent risk factor for medical complications (relative risk $[\mathrm{RR}]=3.6, P=.005$ ), while operative time $>60$ minutes was identified as an independent risk factor for surgical complications after $\mathrm{ACDF}(\mathrm{RR}=4.5, P=.017)$.

Conclusions: The results of this study demonstrate that older age and longer operative time were independent risk factors for medical and surgical complications, respectively, following ACDF. Patients with these risk factors should be counseled regarding their increased risk of postoperative complications and should undergo more vigilant monitoring to aid in complication avoidance.
\end{abstract}

Level of Evidence: 3.

Clinical Relevance: Surgeons should consider the elevated risk of postoperative complications in $>50$ years old patients and $>60$ min procedures.

Minimally Invasive Surgery

Keywords: ACDF, patient age, 2-level, multilevel, CCI, operative time

\section{INTRODUCTION}

Anterior cervical discectomy and fusion (ACDF) is a commonly used procedure for the treatment of cervical degenerative disease. Previous reports have supported the efficacy of ACDF procedures in regard to clinical outcomes and fusion rates. ${ }^{1-6}$ Additionally, ACDF has been proven to be a costeffective surgical procedure compared with other widely accepted health care interventions. ${ }^{7}$ The relative effectiveness of $\mathrm{ACDF}$ procedures has led to an approximate sevenfold increase in its use since $1990 .^{8}$ With this increasing use, ACDF has become the dominant therapeutic technique for cervical degenerative pathology compared with other modalities. $^{9}$

Intraoperative and postoperative complications after ACDF are associated with worsened clinical outcomes, along with subsequent increases in health care resource use and costs. ${ }^{10-13}$ As such, the identification of predictive factors for complications after ACDF procedures has become an area of 
interest within the spine literature. Many previous studies analyzing complication incidence after ACDF have been performed using administrative databases, which typically have short follow-up periods of 30-90 days postoperatively. ${ }^{14-16}$ Additionally, many of the previous investigations identifying risk factors for complications after ACDF have been focused on single predictor variables. ${ }^{14}$

To our knowledge, there have been no previous studies identifying risk factors for medical and surgical complications after ACDF in populations with prolonged follow up. As such, the purpose of this investigation is to determine predictive factors for the incidence of medical and surgical complications up to 2 years postoperatively in patients undergoing $\mathrm{ACDF}$ procedures.

\section{MATERIALS AND METHODS}

\section{Patient Selection}

Institutional review board approval (ORA \#14051301) was obtained for this study. A prospectively maintained database of all patients undergoing primary, 1-2-level ACDF procedures from 2008 to 2015 for degenerative pathology was retrospectively reviewed. All procedures were performed by a single surgeon. Patients were excluded from this analysis if they had nondegenerative surgical indications such as trauma, or if 2 years had not elapsed since their index ACDF procedure.

\section{Data Collection}

Patient characteristics were identified from the prospectively maintained surgical registry. Patients were grouped based on demographic, comorbidity, and operative characteristics. Demographic variables included age ( $\leq 50$ years, $>50$ years), sex, body mass index $\left(<30 \mathrm{~kg} / \mathrm{m}^{2}, \geq 30 \mathrm{~kg} / \mathrm{m}^{2}\right)$, and smoking status. Comorbidity variables included American Society of Anesthesiologists (ASA) score $(\leq 2,>2)$, Charlson Comorbidity Index (CCI; $<2, \geq 2$ ), presence of myelopathy, diagnosis of hypertension, and diagnosis of diabetes mellitus. A modified version of the CCI was used with the age component removed. This allowed for both age and modified CCI to be used as independent variables in subsequent statistical analyses. Operative characteristics included preoperative visual analog scale pain score $(<7, \geq 7)$, operative duration $(\leq 60$ minutes, $>60$ minutes), estimated intraoperative blood loss
$(<50 \mathrm{~mL}, \geq 50 \mathrm{~mL}$ ), and the number of operative levels (1 level, 2 levels).

Intraoperative and postoperative complication incidence was determined up to 2 years postoperatively after each patient's respective ACDF procedure. Medical complications included: aspiration or reintubation, transient urinary retention, urinary tract infection, acute renal failure, postoperative transfusion requirement, altered mental status, deep venous thrombosis, pulmonary embolism, pneumothorax, arrhythmia, ileus, and pneumonia. Of note, transient urinary retention was defined as difficulty voiding postoperatively with requirement for recatheterization. Surgical complications included: intraoperative durotomy, dysphagia, epidural hematoma, instrumentation failure, surgical site infection, new onset neurologic dysfunction, musculoskeletal or bone pathology, and pseudarthrosis. Dysphagia was considered a complication if there was record of 1 of the following during the inpatient stay: failed swallow evaluation, necessity for parenteral nutrition, or failure to progress to a solid diet. Instrumentation failure was considered a complication if reoperation was required secondary to new onset symptomatology. Surgical site infection was considered a complication if an intervention such as an incision and drainage procedure was required postoperatively. Finally, pseudarthrosis was identified as a complication if the resulting nonunion was associated with symptomatology requiring reoperation. Symptomatic pseudarthrosis was initially detected via computed tomography (CT) scan at 6 months or 1 year postoperatively.

\section{Statistical Analysis}

Statistical analysis was performed using Stata/ $\mathrm{MP}^{\circledR} 13.1$ for Mac (StataCorp LP, College Station, TX). The number of patients within each demographic, comorbidity, and operative characteristic group were described using descriptive statistics. The incidence of each medical and surgical complication was described using descriptive statistics. Bivariate Poisson regression with robust error variance was used to determine if an association existed between patient characteristics and complication rate after ACDF procedures. Independent predictors of medical or surgical complications were identified using a backwards, stepwise regression model that initially included all patient characteristics as predictors. In this analysis, variables with the highest $P$ values were excluded until only those with 
Table 1. Patient population.

\begin{tabular}{|c|c|}
\hline Parameter & No. $(\%), \mathbf{N}=310$ \\
\hline \multicolumn{2}{|l|}{ Age } \\
\hline$\leq 50 \mathrm{y}$ & $159(51.3)$ \\
\hline$>50 \mathrm{y}$ & $151(48.7)$ \\
\hline \multicolumn{2}{|l|}{ Sex } \\
\hline Male & $171(55.2)$ \\
\hline Female & $139(44.8)$ \\
\hline \multicolumn{2}{|l|}{ Body mass index } \\
\hline$<30 \mathrm{~kg} / \mathrm{m}^{2}$ & $181(58.4)$ \\
\hline$\geq 30 \mathrm{~kg} / \mathrm{m}^{2}$ & $129(41.6)$ \\
\hline \multicolumn{2}{|l|}{ Current smoker } \\
\hline No & $246(79.4)$ \\
\hline Yes & $64(20.6)$ \\
\hline \multicolumn{2}{|l|}{ ASA score } \\
\hline$\leq 2$ & $253(81.6)$ \\
\hline$>2$ & $57(18.4)$ \\
\hline \multicolumn{2}{|c|}{ Ageless Charlson Comorbidity Index } \\
\hline$<2$ & $145(46.8)$ \\
\hline$>2$ & $165(53.2)$ \\
\hline \multicolumn{2}{|l|}{ Hypertension } \\
\hline No & $201(64.8)$ \\
\hline Yes & $109(35.2)$ \\
\hline \multicolumn{2}{|l|}{ Diabetic status } \\
\hline No diabetes mellitus & $268(86.5)$ \\
\hline Diabetes mellitus & $42(13.5)$ \\
\hline \multicolumn{2}{|l|}{ Presence of myelopathy } \\
\hline No myelopathy & $126(40.7)$ \\
\hline Myelopathy & $184(59.3)$ \\
\hline \multicolumn{2}{|c|}{ Preoperative VAS pain score } \\
\hline$<7$ & $143(47.2)$ \\
\hline$\geq 7$ & $160(52.8)$ \\
\hline \multicolumn{2}{|l|}{ Operative duration } \\
\hline$\leq 60 \min$ & $157(50.7)$ \\
\hline$>60 \mathrm{~min}$ & $153(49.3)$ \\
\hline \multicolumn{2}{|l|}{ Estimated blood loss } \\
\hline$<50 \mathrm{~mL}$ & $71(22.9)$ \\
\hline$\geq 50 \mathrm{~mL}$ & $239(77.1)$ \\
\hline \multicolumn{2}{|c|}{ Number of operative levels } \\
\hline 1 level & $173(55.8)$ \\
\hline 2 levels & $137(44.2)$ \\
\hline
\end{tabular}

Abbreviations: ASA, American Society of Anesthesiologists; VAS, visual analog scale.

$P<.05$ remained. The level of significance was set at $P<.05$.

\section{RESULTS}

After exclusion of those who had not completed 2 years of follow up, a total of 310 patients were included in this analysis. Demographic, comorbidity, and operative characteristics for the study population are described in Table 1.

The incidence of medical and surgical complications is described in Table 2. The medical complication rate was $8.7 \%$, with the most prominent complication being transient postoperative urinary retention $(\mathrm{n}=24,7.7 \%)$. The surgical complication rate was $5.5 \%$, with the most prominent complication being pseudarthrosis $(\mathrm{n}=7,2.3 \%)$.

Bivariate analyses for predictors of medical and surgical complications are presented in Tables 3 and
Table 2. Incidence of medical and surgical complications.

\begin{tabular}{|c|c|}
\hline Complications & No. $(\%), N=310$ \\
\hline \multicolumn{2}{|l|}{ Medical } \\
\hline Aspiration or reintubation & $2(0.6)$ \\
\hline Transient urinary retention $^{\mathrm{a}}$ & $24(7.7)$ \\
\hline Urinary tract infection & $0(0.0)$ \\
\hline Acute renal failure & $0(0.0)$ \\
\hline Postoperative transfusion & $0(0.0)$ \\
\hline Altered mental status & $1(0.3)$ \\
\hline Deep venous thrombosis & $0(0.0)$ \\
\hline Pulmonary embolism & $0(0.0)$ \\
\hline Pneumothorax & $0(0.0)$ \\
\hline Arrhythmia & $0(0.0)$ \\
\hline Ileus & $0(0.0)$ \\
\hline Pneumonia & $0(0.0)$ \\
\hline \multicolumn{2}{|l|}{ Surgical } \\
\hline Intraoperative durotomy & $2(0.6)$ \\
\hline Dysphagia $^{\mathrm{b}}$ & $4(1.3)$ \\
\hline Epidural hematoma & $1(0.3)$ \\
\hline Instrumentation failure ${ }^{\mathrm{c}}$ & $3(1.0)$ \\
\hline Surgical site infection ${ }^{\mathrm{d}}$ & $0(0.0)$ \\
\hline Neurologic dysfunction & $0(0.0)$ \\
\hline Musculoskeletal or bone & $0(0.0)$ \\
\hline Pseudarthrosis ${ }^{\mathrm{e}}$ & $7(2.3)$ \\
\hline
\end{tabular}

${ }^{\mathrm{a}}$ Transient urinary retention requiring recatheterization.

${ }^{b}$ Dysphagia classification criteria: failed swallow evaluation, requirement for parenteral nutrition, or failure to progress to solid diet.

${ }^{\mathrm{c}}$ Cage subsidence $(\mathrm{n}=2)$ and plate impingement $(\mathrm{n}=1)$ requiring reoperation. ${ }^{\mathrm{d}}$ Surgical site infection requiring subsequent incision and drainage procedures.

${ }^{\text {e}}$ Pseudarthrosis identified via computed tomography scan with resultant

symptomatology requiring a revision fusion procedure at the index level.

4. For medical complications, age $>50$ was a predictor of higher complication incidence (relative risk $[\mathrm{RR}]=3.5,95 \%$ confidence interval $[\mathrm{CI}]=1.45-$ $8.51, P=.005)$. For surgical complications, ageless $\mathrm{CCI} \geq 2(\mathrm{RR}=4.1,95 \% \mathrm{CI}=1.20,14.01, P=.024)$, operative duration $>60$ minutes $(\mathrm{RR}=4.8,95 \% \mathrm{CI}$ $=1.40-16.36, P=.013)$, and 2-level procedures $(\mathrm{RR}$ $=3.0,95 \% \mathrm{CI}=1.10-8.41, P=.033)$ were predictors of higher complication incidence. No other predictors of medical or surgical complications were identified from the collected demographic, comorbidity, or operative variables $(P>.05$ for each).

Multivariate analyses for predictors of medical and surgical complications are presented in Table 5. Age $>50$ years was determined to be an independent predictor of higher medical complication incidence. Operative duration $>60$ minutes was determined to be an independent predictor of higher surgical complication rate. No other independent predictors of medical or surgical complications were identified through the performed multivariate analyses.

\section{DISCUSSION}

$\mathrm{ACDF}$ is the predominant technique used for the treatment of degenerative cervical radiculopathy and myelopathy. ${ }^{9}$ However, complications after ACDF are of significant concern due to their effect 
Table 3. Bivariate analysis for medical complications. ${ }^{a}$

\begin{tabular}{|c|c|c|c|c|}
\hline & $\begin{array}{c}\text { Complication } \\
\text { Rate, \% }\end{array}$ & $\mathbf{R R}$ & $95 \%$ CI & $P$ Value $^{b}$ \\
\hline \multicolumn{5}{|l|}{ Age } \\
\hline$\leq \mathbf{5 0} y$ & 3.8 & Ref & & \\
\hline$>\mathbf{5 0} y$ & 13.3 & 3.5 & $1.45-8.51$ & .005 \\
\hline \multicolumn{5}{|l|}{ Sex } \\
\hline Female & 5.8 & Ref & & \\
\hline Male & 10.5 & 1.8 & $0.82-4.08$ & .141 \\
\hline \multicolumn{5}{|l|}{ Body mass index } \\
\hline$<30 \mathrm{~kg} / \mathrm{m}^{2}$ & 10.5 & Ref & & \\
\hline$\geq 30 \mathrm{~kg} / \mathrm{m}^{2}$ & 5.4 & 0.5 & $0.22-1.19$ & .123 \\
\hline \multicolumn{5}{|l|}{ Current smoker } \\
\hline No & 7.7 & Ref & & \\
\hline Yes & 10.9 & 1.4 & $0.62-3.22$ & .407 \\
\hline \multicolumn{5}{|l|}{ ASA score } \\
\hline$\leq 2$ & 7.9 & Ref & & \\
\hline$\overline{>}_{2}$ & 10.5 & 1.3 & $0.60-3.17$ & .518 \\
\hline \multicolumn{5}{|c|}{ Ageless Charlson Comorbidity Index } \\
\hline$<2$ & 8.2 & Ref & & \\
\hline$\geq 2$ & 8.5 & 1.0 & $0.49-2.15$ & .947 \\
\hline \multicolumn{5}{|l|}{ Hypertension } \\
\hline No & 6.5 & Ref & & \\
\hline Yes & 11.9 & 1.8 & $0.89-3.84$ & .102 \\
\hline \multicolumn{5}{|l|}{ Diabetic status } \\
\hline No diabetes mellitus & 8.2 & Ref & & \\
\hline Diabetes mellitus & 9.5 & 1.2 & $0.42-3.20$ & .774 \\
\hline \multicolumn{5}{|l|}{ Presence of myelopathy } \\
\hline No myelopathy & 5.6 & Ref & & \\
\hline Myelopathy & 10.3 & 1.9 & $0.80-4.30$ & .147 \\
\hline \multicolumn{5}{|c|}{ Preoperative VAS pain score } \\
\hline$<7$ & 9.1 & Ref & & \\
\hline$\geq 7$ & 8.1 & 0.9 & $0.43-1.87$ & .765 \\
\hline \multicolumn{5}{|l|}{ Operative duration } \\
\hline$\leq 60 \mathrm{~min}$ & 7.0 & Ref & & \\
\hline$>60 \min$ & 9.8 & 1.4 & $0.66-2.95$ & .378 \\
\hline \multicolumn{5}{|l|}{ Estimated blood loss } \\
\hline$<50 \mathrm{~mL}$ & 11.3 & Ref & & \\
\hline$\geq 50 \mathrm{~mL}$ & 7.5 & 0.7 & $0.30-1.47$ & .318 \\
\hline \multicolumn{5}{|c|}{ Number of operative levels } \\
\hline 1 level & 8.1 & Ref & & \\
\hline 2 levels & 8.8 & 1.1 & $0.52-2.27$ & .834 \\
\hline
\end{tabular}

Abbreviations: ASA, American Society of Anesthesiologists; CI, confidence interval; ref, reference; RR, relative ratio; VAS, visual analog scale.

${ }^{a}$ Boldface indicates statistical significance.

${ }^{\mathrm{b}} P$ value calculated using Poisson regression with robust error variance.

on both clinical outcomes and health care resource use. $^{10-13}$ As such, the identification of predictive factors for complications is important in developing effective preoperative and postoperative protocols for complication avoidance. The purpose of this study was to determine predictive factors for the incidence of medical and surgical complications up to 2 years after ACDF procedures.

The results of this study indicate that the medical complication rate after ACDF in the present population was $8.7 \%$, with the most prominent complication being transient urinary retention requiring recatheterization. Additionally, the surgical complication rate in the present population was $5.5 \%$, with the most prominent complication being pseudarthrosis. On bivariate and multivariate analysis, age $>50$ years was identified as an independent
Table 4. Bivariate analysis for surgical complications. ${ }^{\text {a }}$

\begin{tabular}{|c|c|c|c|c|}
\hline & $\begin{array}{c}\text { Complication } \\
\text { Rate, \% }\end{array}$ & $\mathbf{R R}$ & $95 \%$ CI & $P$ Value $^{\text {b }}$ \\
\hline \multicolumn{5}{|l|}{ Age } \\
\hline$\leq 50 \mathrm{y}$ & 3.1 & Ref & & \\
\hline$>50 \mathrm{y}$ & 8.0 & 2.5 & $0.91-7.01$ & .075 \\
\hline \multicolumn{5}{|l|}{ Sex } \\
\hline Female & 2.9 & Ref & & \\
\hline Male & 7.6 & 2.6 & $0.88-7.94$ & .083 \\
\hline \multicolumn{5}{|l|}{ Body mass index } \\
\hline$<30 \mathrm{~kg} / \mathrm{m}^{2}$ & 6.6 & Ref & & \\
\hline$\geq 30 \mathrm{~kg} / \mathrm{m}^{2}$ & 3.9 & 0.6 & $0.21-1.62$ & .302 \\
\hline \multicolumn{5}{|l|}{ Current smoker } \\
\hline No & 5.3 & Ref & & \\
\hline Yes & 6.3 & 1.2 & $0.40-3.51$ & .763 \\
\hline \multicolumn{5}{|l|}{ ASA score } \\
\hline$\leq 2$ & 4.4 & Ref & & \\
\hline$>2$ & 10.5 & 2.4 & $0.93-6.28$ & .069 \\
\hline \multicolumn{5}{|c|}{ Ageless Charlson Comorbidity Index } \\
\hline$<2$ & 2.1 & Ref & & \\
\hline$\geq \mathbf{2}$ & 8.5 & 4.1 & $1.20-14.01$ & .024 \\
\hline \multicolumn{5}{|l|}{ Hypertension } \\
\hline No & 5.0 & Ref & & \\
\hline Yes & 6.4 & 1.3 & $0.50-3.30$ & .594 \\
\hline \multicolumn{5}{|l|}{ Diabetic status } \\
\hline No diabetes mellitus & 5.2 & Ref & & \\
\hline Diabetes mellitus & 7.1 & 1.4 & $0.41-4.57$ & .611 \\
\hline \multicolumn{5}{|l|}{ Presence of myelopathy } \\
\hline No myelopathy & 3.2 & Ref & & \\
\hline Myelopathy & 7.1 & 2.2 & $0.74-6.68$ & .154 \\
\hline \multicolumn{5}{|c|}{ Preoperative VAS pain score } \\
\hline$<7$ & 3.5 & Ref & & \\
\hline$\geq 7$ & 6.9 & 2.0 & $0.70-5.53$ & .200 \\
\hline \multicolumn{5}{|l|}{ Operative duration } \\
\hline$\leq 60 \mathrm{~min}$ & 1.9 & Ref & & \\
\hline$>60 \mathrm{~min}$ & 9.2 & 4.8 & $1.40-16.36$ & .013 \\
\hline \multicolumn{5}{|l|}{ Estimated blood loss } \\
\hline$<50 \mathrm{~mL}$ & 1.4 & Ref & & \\
\hline$\geq 50 \mathrm{~mL}$ & 6.7 & 4.8 & $0.64-35.33$ & .128 \\
\hline \multicolumn{5}{|l|}{ Number of operative levels } \\
\hline 1 level & 2.9 & Ref & & \\
\hline 2 levels & 8.8 & 3.0 & $1.10-8.41$ & .033 \\
\hline
\end{tabular}

Abbreviations: ASA, American Society of Anesthesiologists; CI, confidence interval; ref, reference; RR, relative ratio; VAS, visual analog scale.

${ }^{a}$ Boldface indicates statistical significance

${ }^{\mathrm{b}} P$ value calculated using Poisson regression with robust error variance.

predictor of medical complications after ACDF, while operative duration $>60$ minutes was identified as an independent predictor of surgical complications after ACDF.

Older age was identified in this study as an independent risk factor for medical complications after ACDF. This result is supported by the cervical spine literature, with many previous reports identi-

Table 5. Independent risk factors for complications.

\begin{tabular}{lclc}
\hline Complication & RR & 95\% CI & $\boldsymbol{P}$ Value $^{\mathbf{a}}$ \\
\hline Medical, age $>50$ y & 3.6 & $1.48-8.69$ & .005 \\
Surgical, operative time $>60$ min & 4.5 & $1.32-15.64$ & .017
\end{tabular}

Abbreviations: RR, relative risk; CI, confidence interval.

${ }^{\text {a }} P$ value calculated using stepwise Poisson regression with robust error variance controlling for age, gender, smoking status, diabetes mellitus, presence of

myelopathy, hypertension, obesity, American Society of Anesthesiologists score, comorbidity burden, average preoperative pain scores, operative time, estimated blood loss, and number of operative levels. 
fying a similar association. ${ }^{15-22}$ Wang et $\mathrm{al}^{17}$ performed a study of 932,009 patients undergoing anterior or posterior cervical fusion from the Nationwide Inpatient Sample. The authors determined that patients of older age ( $>74$ years) had a higher overall complication rate during the postoperative inpatient stay than patients of younger age. Similarly, Buerba et $\mathrm{al}^{16}$ performed an investigation of 6,253 patients undergoing ACDF from the American College of Surgeons National Surgical Quality Improvement Program (ACS-NSQIP) database. Older patients ( $\geq 65$ years) exhibited an increased risk of $\geq 1$ complication, urinary complications, blood transfusions, reoperations, and extended length of stay. Interestingly, the association between older age and complication rate was present even after adjusting for patient comorbidities. The results of the current investigation, in conjunction with previous findings within the literature, indicate that patient age should be a consideration during preoperative planning for ACDF. Older patients should be counseled regarding their increased risk for medical complications and may also need to be more vigilantly monitored for complications postoperatively. Additionally, further work is necessary to analyze the efficacy of preoperative comorbidity modification in at-risk populations such as older patients undergoing ACDF procedures. ${ }^{16}$

The current study illustrated increased operative duration was an independent risk factor for surgical complications after ACDF, a finding that is corroborated by the cervical spine literature. ${ }^{23-26}$ O'Neill et al $^{25}$ performed a retrospective review of ACDF procedures to investigate risk factors for developing anterior cervical hematomas. The results of the study illustrated that the risk of hematoma was significantly greater in patients with prolonged operative time (2.5 versus 2.0 hours, $P=.049)$. In a retrospective study using the ACS-NSQIP database, Martin et $\mathrm{al}^{24}$ identified operative times longer than 120 minutes to be a significant risk factor for complications following ACDF (adjusted odds ratio $[\mathrm{aOR}]=1.94,95 \% \mathrm{CI}=1.25-2.99)$. Prolonged operative time has also been associated with increased risk of complications in the elderly population. Using the ACS-NSQIP database, Bernstein et $\mathrm{al}^{23}$ identified 1786 ACDF patients $\geq 65$ years of age, of which $175(9.8 \%)$ experienced complications. Patients with increased operative times were reported to have an increased risk of complications $(\mathrm{OR}=3.54,95 \% \mathrm{CI}=2.27-5.53)$. Although the association between operative duration and risk of complications in cervical spine surgery has not been well characterized, efforts should be made to minimize unnecessary prolongations in operative time in order to prevent undue harm.

This study also identified 2-level procedures as a risk factor for surgical complications after ACDF compared with 1-level procedures. This association is also supported by the cervical spine literature, which has demonstrated increased rates of complications and pseudarthrosis after multilevel procedures when compared with single-level procedures. ${ }^{14,27-29}$ Veeravagu et $\mathrm{al}^{14}$, in a study of 28,777 patients from the Marketscan database, determined that patients undergoing multilevel ACDF were more likely to develop postoperative complications within the first 30 postoperative days. Additionally, multilevel ACDF patients were significantly more likely to undergo revision procedures within periods encompassing 30 days and 2 years postoperatively. In an investigation identifying risk factors for pseudarthrosis, Zigler et $\mathrm{al}^{27}$ analyzed 186 patients undergoing either 1- or 2-level ACDF. At 6 months and 1 year postoperatively, patients undergoing 2-level ACDF were demonstrated to have significantly lower fusion rates compared with those undergoing 1-level ACDF. The origin of the differences in surgical complication and pseudarthrosis rates between 1- and 2-level procedures is unknown but has been postulated to be associated with increased surgical invasiveness and greater micromotion in multilevel constructs. ${ }^{29}$ Nonetheless, patients undergoing 2-level procedures should be appropriately counseled regarding their increased risk for surgical complications after ACDF procedures.

Interestingly, smoking status was not associated with the incidence of either medical or surgical complications within our study population. Smoking status has received significant attention within the spine literature, with many studies analyzing the effect of smoking on postoperative outcomes and fusion rates after spinal procedures. Similar to the present study, other studies have failed to find an association between smoking and increased complication incidence or decreased fusion rates after ACDF procedures. ${ }^{30-32}$ Luszcyzk et al ${ }^{32}$ analyzed fusion rates in smokers and nonsmokers after ACDF. In that study, no significant differences in 
arthrodesis rates existed between smokers and nonsmokers up to 24 months postoperatively. Purvis et $\mathrm{al}^{30}$ used the ACS-NSQIP database and multivariate analyses to determine that current smokers did not have increased rates of any complication or major complications in a large cohort of patients undergoing ACDF. However, the authors did note that current nonsmokers who had previously smoked did have a higher risk of major complications postoperatively. In the present study, previous smokers that had abstained from smoking for at least 6 months prior to their procedure were included in the nonsmoker cohort. This may have contributed to the lack of association identified between smoking and complication rates.

The present study also determined that patient comorbidity as measured by CCI was a predictor of surgical complications after ACDF procedures. Previous studies have reported similar findings, with investigations using general spine surgery cohorts demonstrating an association between higher comorbidity burden and complication rate. ${ }^{33-38}$ Whitmore et $\mathrm{al}^{33}$, in an investigation of 226 spine cases, determined that increasing CCI was associated with increased incidence of any complication and minor complications. In regard to ACDF-specific cohorts, increasing comorbidity burden has been associated with increased rates of 30-day readmission postoperatively. ${ }^{39,40}$ The results of our study may indicate that comorbidities have an effect on complication incidence, even in relatively less invasive procedures such as ACDF. However, further study regarding comorbidity burden and the incidence of postoperative complications is necessary in procedurespecific populations with long-term follow up.

This study is not without limitations. First, the retrospective nature of this study may place the analysis at risk of selection bias. Second, all patients were evaluated and operated on by a single surgeon, thus limiting the generalizability of the study findings. Third, the criteria for which events were considered complications was devised by the senior author (K.S.) and may be unique to our practice setting. As such, the observed complication rate in this study may differ from other investigations that used different criteria for complication determination. Lastly, patients who experienced complications postoperatively may have received care at other health care facilities. As such, our reported complication rate may be an underestimation of the true complication rate.

\section{CONCLUSIONS}

The results of this study indicate that older patient age is predictive of increased medical complication rate after ACDF procedures. Additionally, prolonged operative duration is predictive of increased surgical complication rate up to 2 years postoperatively after ACDF. Practitioners can use this information to maximize both preoperative and postoperative care protocols to aid in complication prevention. Preoperatively, patients with these risk factors should be counseled appropriately regarding their increased complication risk. Postoperatively, these patients should be monitored more vigilantly to aid in complication prevention, both during the initial postoperative period and at follow-up evaluations. Further investigation is still required to determine specific methods for complication avoidance in these at-risk patient populations.

\section{REFERENCES}

1. Barnes B, Haid RW, Rodts GE, et al. Early results using the Atlantis anterior cervical plate system. Neurosurg Focus. 2002;12(1):E13.

2. Papadopoulos EC, Huang RC, Girardi FP, et al. Threelevel anterior cervical discectomy and fusion with plate fixation: radiographic and clinical results. Spine (Phila Pa 1976). 2006;31(8):897-902.

3. Samartzis D, Shen FH, Matthews DK, et al. Comparison of allograft to autograft in multilevel anterior cervical discectomy and fusion with rigid plate fixation. Spine $J$. 2003;3(6):451-459.

4. Samartzis D, Shen FH, Lyon C, et al. Does rigid instrumentation increase the fusion rate in one-level anterior cervical discectomy and fusion? Spine J. 2004;4(6):636-643.

5. Samartzis D, Shen FH, Goldberg EJ, et al. Is autograft the gold standard in achieving radiographic fusion in one-level anterior cervical discectomy and fusion with rigid anterior plate fixation? Spine (Phila Pa 1976). 2005;30(15):1756-1761.

6. Shen FH, Samartzis D, Khanna N, et al. Comparison of clinical and radiographic outcome in instrumented anterior cervical discectomy and fusion with or without direct uncovertebral joint decompression. Spine J. 2004;4(6):629-635.

7. Carreon LY, Anderson PA, Traynelis VC, et al. Costeffectiveness of single-level anterior cervical discectomy and fusion five years after surgery. Spine (Phila Pa 1976). 2013;38(6):471-475.

8. Marawar S, Girardi FP, Sama AA, et al. National trends in anterior cervical fusion procedures. Spine (Phila Pa 1976). 2010;35(15):1454-1459.

9. Nesterenko SO, Riley LH, 3rd, Skolasky RL. Anterior cervical discectomy and fusion versus cervical disc arthroplasty: current state and trends in treatment for cervical disc pathology. Spine (Phila Pa 1976). 2012;37(17):1470-1474.

10. Nanda A, Sharma M, Sonig A, et al. Surgical complications of anterior cervical diskectomy and fusion for 
cervical degenerative disk disease: a single surgeon's experience of 1,576 patients. World Neurosurg. 2014;82(6):1380-1387.

11. Lied B, Sundseth J, Helseth E. Immediate (0-6 h), early (6-72 h) and late $(>72 \mathrm{~h}$ ) complications after anterior cervical discectomy with fusion for cervical disc degeneration; discharge six hours after operation is feasible. Acta Neurochir (Wien). 2008;150(2):111-118; discussion 118.

12. Fountas KN, Kapsalaki EZ, Nikolakakos LG, et al. Anterior cervical discectomy and fusion associated complications. Spine (Phila Pa 1976). 2007;32(21):2310-2317.

13. Daniels AH, Kawaguchi S, Contag AG, et al. Hospital charges associated with "never events": comparison of anterior cervical discectomy and fusion, posterior lumbar interbody fusion, and lumbar laminectomy to total joint arthroplasty. $J$ Neurosurg Spine. 2016;25(2):165-169.

14. Veeravagu A, Cole T, Jiang B, et al. Revision rates and complication incidence in single- and multilevel anterior cervical discectomy and fusion procedures: an administrative database study. Spine J. 2014;14(7):1125-1131.

15. Lim S, Kesavabhotla K, Cybulski GR, et al. Predictors for airway complications following single- and multilevel anterior cervical discectomy and fusion. Spine (Phila $\mathrm{Pa}$ 1976). 2017;42(6):379-384.

16. Buerba RA, Giles E, Webb ML, et al. Increased risk of complications after anterior cervical discectomy and fusion in the elderly: an analysis of 6253 patients in the American College of Surgeons National Surgical Quality Improvement Program database. Spine (Phila Pa 1976). 2014;39(25):2062-2069.

17. Wang MC, Chan L, Maiman DJ, et al. Complications and mortality associated with cervical spine surgery for degenerative disease in the United States. Spine (Phila Pa 1976). 2007;32(3):342-347.

18. Romano PS, Campa DR, Rainwater JA. Elective cervical discectomy in California: postoperative in-hospital complications and their risk factors. Spine (Phila Pa 1976). 1997;22(22):2677-2692.

19. Fineberg SJ, Oglesby M, Patel AA, et al. Outcomes of cervical spine surgery in teaching and non-teaching hospitals. Spine (Phila Pa 1976). 2013;38(13):1089-1096.

20. Di Capua J, Somani S, Kim JS, et al. Predictors for patient discharge destination following elective anterior cervical discectomy and fusion. Spine (Phila Pa 1976). 2017;42(20):1538-1544.

21. Baron EM, Soliman AM, Gaughan JP, et al. Dysphagia, hoarseness, and unilateral true vocal fold motion impairment following anterior cervical diskectomy and fusion. Ann Otol Rhinol Laryngol. 2003;112(11):921-926.

22. Arnold PM, Rice LR, Anderson KK, et al. Factors affecting hospital length of stay following anterior cervical discectomy and fusion. Evid Based Spine Care J. 2011;2(3):1118.

23. Bernstein DN, Thirukumaran C, Saleh A, et al. Complications and readmission after cervical spine surgery in elderly patients: an analysis of 1786 patients. World Neurosurg. 2017;103:859-868 e8.

24. Martin CT, Pugely AJ, Gao Y, et al. Thirty-day morbidity after single-level anterior cervical discectomy and fusion: identification of risk factors and emphasis on the safety of outpatient procedures. J Bone Joint Surg Am. 2014;96(15):1288-1294.

25. O’Neill KR, Neuman B, Peters C, et al. Risk factors for postoperative retropharyngeal hematoma after anterior cervical spine surgery. Spine (Phila Pa 1976). 2014;39(4):E246-252.

26. Rihn JA, Kane J, Albert TJ, et al. What is the incidence and severity of dysphagia after anterior cervical surgery? Clin Orthop Relat Res. 2011;469(3):658-665.

27. Zigler JE, Rogers RW, Ohnmeiss DD. Comparison of 1level versus 2-level anterior cervical discectomy and fusion: clinical and radiographic follow-up at 60 months. Spine (Phila Pa 1976). 2016;41(6):463-469.

28. Shen HX, Buchowski JM, Yeom JS, et al. Pseudarthrosis in multilevel anterior cervical fusion with rhBMP-2 and allograft: analysis of one hundred twenty-seven cases with minimum two-year follow-up. Spine (Phila Pa 1976). 2010;35(7):747-753.

29. Lee DH, Cho JH, Hwang CJ, et al. What is the fate of pseudarthrosis detected 1 year after anterior cervical discectomy and fusion? Spine (Phila Pa 1976). 2017;43(1):E23-E28.

30. Purvis TE, Rodriguez HJ, Ahmed AK, et al. Impact of smoking on postoperative complications after anterior cervical discectomy and fusion. J Clin Neurosci. 2017;38:106-110.

31. Peolsson A, Hedlund R, Vavruch L. Prediction of fusion and importance of radiological variables for the outcome of anterior cervical decompression and fusion. Eur Spine J. 2004;13(3):229-234.

32. Luszczyk M, Smith JS, Fischgrund JS, et al. Does smoking have an impact on fusion rate in single-level anterior cervical discectomy and fusion with allograft and rigid plate fixation? Clinical article. J Neurosurg Spine. 2013;19(5):527531.

33. Whitmore RG, Stephen JH, Vernick C, et al. ASA grade and Charlson Comorbidity Index of spinal surgery patients: correlation with complications and societal costs. Spine J. 2014;14(1):31-38.

34. Veeravagu A, Patil CG, Lad SP, et al. Risk factors for postoperative spinal wound infections after spinal decompression and fusion surgeries. Spine (Phila Pa 1976). 2009;34(17):1869-1872.

35. Tang H, Zhu J, Ji F, et al. Risk factors for postoperative complication after spinal fusion and instrumentation in degenerative lumbar scoliosis patients. J Orthop Surg Res. 2014;9:15.

36. Schoenfeld AJ, Ochoa LM, Bader JO, et al. Risk factors for immediate postoperative complications and mortality following spine surgery: a study of 3475 patients from the National Surgical Quality Improvement Program. J Bone Joint Surg Am. 2011;93(17):1577-1582.

37. Fu KM, Smith JS, Polly DW Jr, et al. Correlation of higher preoperative American Society of Anesthesiology grade and increased morbidity and mortality rates in patients undergoing spine surgery. J Neurosurg Spine. 2011;14(4):470474.

38. Campbell PG, Yadla S, Nasser R, et al. Patient comorbidity score predicting the incidence of perioperative complications: assessing the impact of comorbidities on complications in spine surgery. $J$ Neurosurg Spine. 2012;16(1):37-43.

39. Phan K, Kim JS, Lee NJ, et al. Relationship between ASA scores and 30-day readmissions in patients undergoing anterior cervical discectomy and fusion. Spine (Phila Pa 1976). 2017;42(2):85-91.

40. Lovecchio F, Hsu WK, Smith TR, et al. Predictors of 
thirty-day readmission after anterior cervical fusion. Spine (Phila Pa 1976). 2014;39(2):127-133.

Disclosures and COI: No funds were received in support of this work. No benefits in any form have been or will be received from any commercial party related directly or indirectly to the subject of this manuscript.

IRB Approval: ORA \#14051301.

Corresponding Author: Kern Singh, MD, Department of Orthopaedic Surgery, Rush Univer- sity Medical Center, 1611 W. Harrison St, Suite \#300, Chicago, IL 60612. Phone: (312) 432-2373; Fax: (708) 409-5179; Email: kern.singh@rushortho. com.

Published 30 June 2020

This manuscript is generously published free of charge by ISASS, the International Society for the Advancement of Spine Surgery. Copyright (C) 2020 ISASS. To see more or order reprints or permissions, see http://ijssurgery.com. 